\title{
Cooled Dye Laser
}

\author{
Ch. Heinsohn and J. Weber \\ Optisches Institut der Technischen Universität Berlin
}

(Z. Naturforsch. 30 a, 606-611 [1975] ; received April 1, 1975)

\begin{abstract}
Wavelength spectrum, threshold intensity, photobleaching and long pulse emission in cooled dye matrices (rhodamin $\mathrm{B}$, rhodamin $6 \mathrm{G}$, cresylviolet) as a function of temperature $\left(+25^{\circ} \mathrm{C}\right.$ to $-140^{\circ} \mathrm{C}$ ) was investigated. Absorption spectra were also obtained.
\end{abstract}

The emission characteristic of a laser-excited organic dye laser at room temperature is described in a number of experiments ${ }^{\mathbf{1}}$, but only a few investigations are made on cooled dye lasers. First experiments were made by Schappert et al. ${ }^{2}$. They investigated the frequency shift of $3,3^{\prime}$ diethylthiatricarbocyanine iodide in the range from $-117^{\circ} \mathrm{C}$ to $+78{ }^{\circ} \mathrm{C}$. Aristov et al. ${ }^{3}$ examined rhodamin $\mathrm{B}$ in an alcoholic solution between $-120^{\circ} \mathrm{C}$ and $+30{ }^{\circ} \mathrm{C}$ by exciting with a flashlamp. Huth et al. ${ }^{4}$ reported the influence of temperature $\left(-10{ }^{\circ} \mathrm{C}\right.$ to $\left.+30{ }^{\circ} \mathrm{C}\right)$ on the emission wavelength, output energy and threshold energy of rhodamin B, rhodamin $6 \mathrm{G}$ and 7-diethylamino-4-methylcoumarin. Only rhodamin B was influenced by temperature. Ferguson et al. ${ }^{5}$ studied anthracen up to $-125^{\circ} \mathrm{C}$.

We wish to report on measurements of rhodamin B, rhodamin $6 \mathrm{G}$ and cresylviolet in cooled epoxy and polyester matrices. The temperature range was $+25^{\circ} \mathrm{C}$ to $-140{ }^{\circ} \mathrm{C}$.

\section{Experimental Arrangement}

To prepare the matrices we used a two component epoxy-resin for rhodamin B and rhodamin $6 \mathrm{G}$ and polyester for cresylviolet. The resin was mixed with methanolic dye solutions, and afterwards methanol was desgassed in vacuum. The mould was of PMMA prepared with a special isolating lac. The resulting matrices were $0.8 \mathrm{~cm} \times 1 \mathrm{~cm} \times 5 \mathrm{~cm}$. The surfaces were not polished after polymerisation $(24 \mathrm{~h})$ and it was possible to coat them with 15 layers of thoriumfluoride and $\mathrm{ZnS}$. The resulting reflection was $R>99 \%$. The layers were not damaged by cooling to $-140^{\circ} \mathrm{C}$ if they were placed in vacuum, but immediately destroyed when they were cooled at

Reprint requests to Dr. J. Weber, Technische Universität Berlin, Fachbereich Physik (4), Optisches Institut, D-1000 Berlin 12, Straße des 17. Juni 135. normal pressure. Inside the matrices we observed optical inhomogeneities. They influenced the threshold intensity.

To cool the matrices they were mounted on a hollow copper block, filled with liquid nitrogen inside and then placed in an evacuated cylinder (Figure 1). The temperature was measured with a calibrated thermocouple at the excited surface. The low thermal conductivity of the epoxy (polyester) caused a temperature difference of $56^{\circ}$ between the excited surface and the cooled backside. So the lowest temperature the surface could be cooled down to was $-140{ }^{\circ} \mathrm{C}$. It took 15 minutes to reach this temperature.

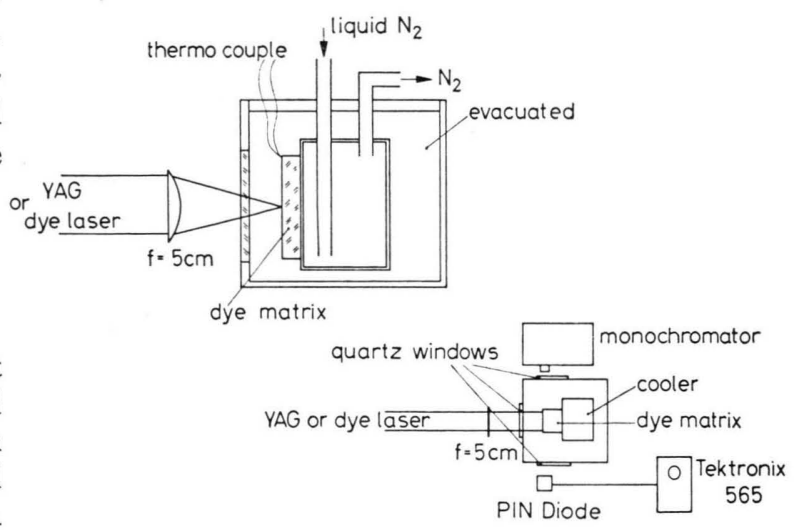

Fig. 1. Experimental arrangement.

To excite the matrices we used a frequency doubled Nd-YAG laser $(t=20 \mathrm{nsec}, \lambda=5300 \mathrm{AE}$, $E_{\max }=6 \mathrm{~m}$ Joule $)$ or a dye laser $(t=2.2 \mu \mathrm{sec}$, $E_{\max }=5 \mathrm{~m}$ Joule). The exciting pulse was focused on the matrix surface with a cylindrical lens. The emission wavelength was measured with a monochromator and an RCA 7265 multiplier, the output with a calibrated thermopile or a PIN diode.

It was possible to reduce the output energy of the pumping pulse continuously by a polarization filter. 


\section{Singlet State Absorption Spectra}

The molecular extinction coefficient is calculated as

$$
\varepsilon=(1 / N \cdot l) \cdot \ln T^{-1}\left[\mathrm{~cm}^{2}\right],
$$

$N$ concentration (molecules $/ \mathrm{cm}^{3}$ ), $T$ transmission, $l$ thickness of the matrix $(\mathrm{cm})$.

At room temperature no difference in shape and position of $\varepsilon$ between methanolic solution and matrix was found. Only the absolute values of $\varepsilon$ in the matrix were always smaller than in the solution; we suppose that there was a chemical reaction between the dyes and the epoxy (polyester).

Rhodamin 6G: With decreasing temperature the maximum shifts to longer wavelength $(\Delta \lambda=90 \AA$ at $T=-140{ }^{\circ} \mathrm{C}$ ), the maximum extinction coefficient changes from $\varepsilon_{25}=2.8 \cdot 10^{-16} \mathrm{~cm}^{2}$ to $\varepsilon_{-140}=$ $3.6 \cdot 10^{-16} \mathrm{~cm}^{2}$ (Figure 2). Lewschin 6 observed a similar shift $(\Delta \lambda=23 \AA)$ by cooling alcoholic solu-

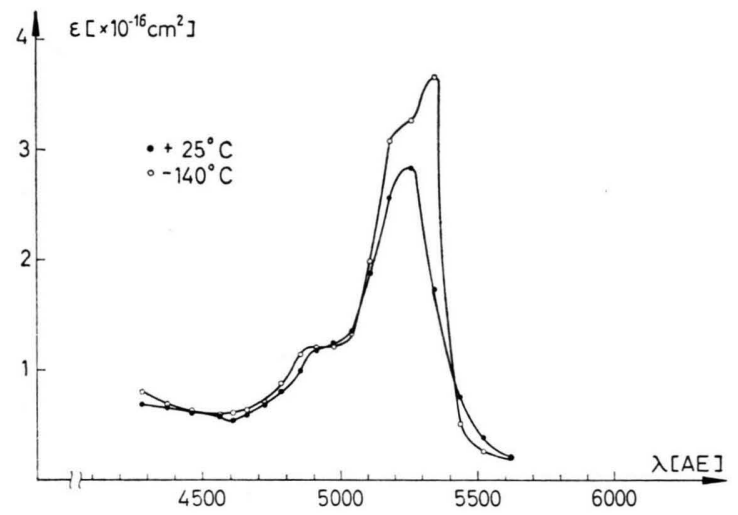

Fig. 2. Molecular singlet state extinction coefficient of rhodamin $6 \mathrm{G}$ from measurements with a $1 \cdot 10^{-4}$ molar epoxy matrix at $T=+25{ }^{\circ} \mathrm{C}$ and $T=-140{ }^{\circ} \mathrm{C}$.

tions from $+22{ }^{\circ} \mathrm{C}$ to $-67{ }^{\circ} \mathrm{C}$. The relative fluorescence spectrum $\left(1 \cdot 10^{-3} \mathrm{~mol}\right)$ was measured at $+25{ }^{\circ} \mathrm{C}$ and $-140{ }^{\circ} \mathrm{C}$ (Figure 3 ). The area under the curves and hence the quantum yield increased by approximately $6 \%$. The fluorescence maximum shifts to shorter wavelengths $(\Delta \lambda=60 \AA)$.

Rhodamin B (Figure 4): The extinction coefficient changes from $\varepsilon_{25}=2.1 \cdot 10^{-16} \mathrm{~cm}^{2}$ to $\varepsilon_{-140}=$ $2.5 \cdot 10^{-16} \mathrm{~cm}^{2}$, a shift of the maximum was not observed. Speas ${ }^{7}$ measured a slight shift to longer wavelengths in dilute alcoholic solutions.

At $\lambda=5150 \AA$ a second weak maximum arises at $T=-140{ }^{\circ} \mathrm{C}$, which is probably produced by the dimer of rhodamin B molecules ${ }^{8}$.

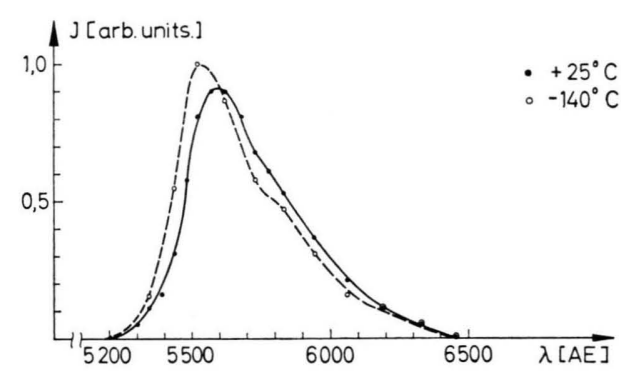

Fig. 3. Relative fluorescence spectrum of rhodamin 6G from measurements with a $1 \cdot 10^{-4}$ molar epoxy matrix at $T=+25^{\circ} \mathrm{C}$ and $T=-140^{\circ} \mathrm{C}$.

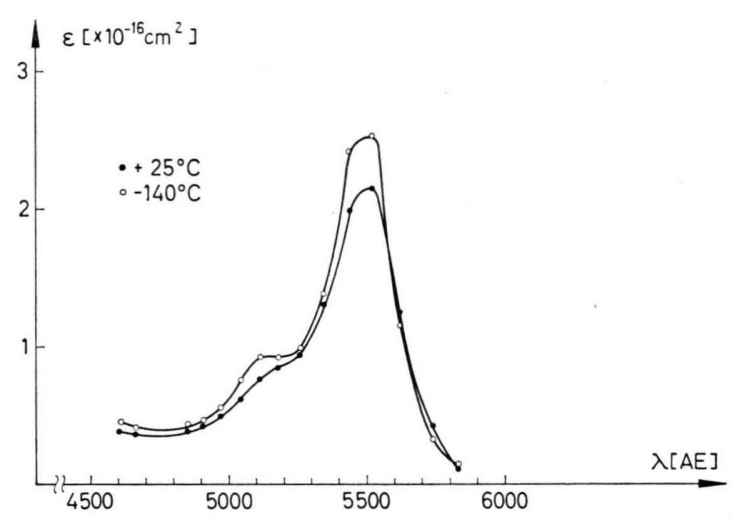

Fig. 4. Molecular singlet state extinction coefficient of rhodamin B from measurements with a $1 \cdot 10^{-4}$ molar epoxy matrix at $T=+25^{\circ} \mathrm{C}$ and $T=-140^{\circ} \mathrm{C}$.

Cresylviolet (Figure 5) : A shift is not observed, the maximum extinction coefficient changes from $\varepsilon_{25}=3.1 \cdot 10^{-17} \mathrm{~cm}^{2}$ to $\varepsilon_{-140}=3.5 \cdot 10^{-17} \mathrm{~cm}^{2}$.

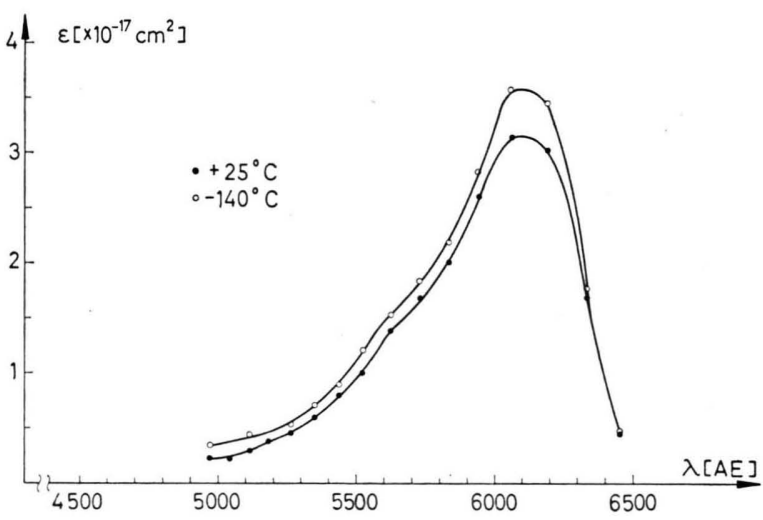

Fig. 5. Molecular singlet state extinction coefficient of cresylviolet from measurements with a $1 \cdot 10^{-4}$ molar polyester matrix at $T=+25^{\circ} \mathrm{C}$ and $T=-140^{\circ} \mathrm{C}$. 


\section{Threshold intensity}

At first we compared the threshold intensities of a methanolic rhodamin $6 \mathrm{G}$ solution $\left(1 \cdot 10^{-3} \mathrm{~mol}\right)$ and the corresponding matrix at room temperature. The quartzglas cell and the matrix had identical dimensions and were both directly coated with dielectric layers $(R>99 \%)$. To obtain beam uniformity on the sample the beam was expanded to $2.0 \mathrm{~cm}$ and then masked with a $0.1 \mathrm{~cm}$ slit; the excited area was $1 \mathrm{~cm} \times 0.1 \mathrm{~cm}$. Continuous reducing of the beam intensity was obtained with a polarization filter.

The threshold intensity depends on the optical inhomogeneities in the matrix and it was found that for the matrix the intensity is $60 \%-70 \%$ greater than for methanolic solutions. This result agrees with the smaller fluorescence lifetime in epoxy $\left(\tau_{\text {epoxy }}=3.5 \mathrm{nsec} ; \tau_{\text {methanol }}=5.8 \mathrm{nsec}^{9}\right)$.

The threshold intensity of laser dyes excited with short pulses is given by ${ }^{10}$ :

$$
J=\frac{1}{N \varepsilon_{3} \tau}\left\{\frac{N \varepsilon_{1}-\frac{1}{2} \ln \left[R_{1} R_{2}(1-V)^{2}\right] l^{-1}}{\frac{\lambda^{4} E \eta}{8 \pi \tau c}+\varepsilon_{1}}\right\},
$$

$N$ dye concentration, $\varepsilon_{1}$ singlet state extinction coefficient for the emission wavelength, $\varepsilon_{3}$ singlet state extinction coefficient for the exciting wavelength $(\lambda=5300 \AA), \tau$ fluorescence lifetime, $R_{1}, R_{2}$ mirror reflectance, $V$ resonator losses, $l$ length of active region, $\lambda$ emission wavelength, $\eta$ refractive index, $E$ normalized fluorescence spectrum

$$
\int_{0}^{\infty} E(\lambda) \mathrm{d} \lambda=\Phi
$$

$\Phi$ quantum yield.

We used this equation to calculate the relative threshold intensity of rhodamin $6 \mathrm{G} 1 \cdot 10^{-3}$ molar in epoxy as a function of temperature. $\varepsilon_{1}, \varepsilon_{3}, \lambda, \tau$ and $E$ change with temperature, and we supposed that $R_{1}, R_{2}, \eta$ and $V$ do not depend on temperature. $\varepsilon_{1}$ and $\varepsilon_{3}$ are taken from Fig. 2, $\lambda$ is plotted in Fig. 8 and the fluorescence lifetime is published by Theiß et al. ${ }^{9}$. The relative change of $E(\lambda)$ is plotted in Fig. 3, the absolute values are taken from Snavely ${ }^{11}$. The values used for the calculation are summarized in Table 1 for $T=+25{ }^{\circ} \mathrm{C}$ and $T=-140{ }^{\circ} \mathrm{C}$.

At $T=-140{ }^{\circ} \mathrm{C}$ the theoretical curve is fitted to the experimental; in that case we found good agreement of the calculation and the experiment. The calculation demonstrates that the decrease of the threshold intensity is essentially induced by the fluorescence lifetime $\tau$ and the extinction coefficient $\varepsilon_{3}$.

Below $T=-120^{\circ} \mathrm{C}$ the fluorescence lifetime is not dependent on temperature ${ }^{9}$, that means there is no interaction between the host material and the rhodamin molecules. Consequently a further reduction of the threshold intensity (below $T=-120^{\circ} \mathrm{C}$ ) is only possible because the Boltzmann distribution in the singlet $S_{1}$ and $S_{0}$ state changes.

Experimental results for further concentrations of rhodamin $6 \mathrm{G}$ and rhodamin $\mathrm{B}$ are shown in Figures 6 and 7 .

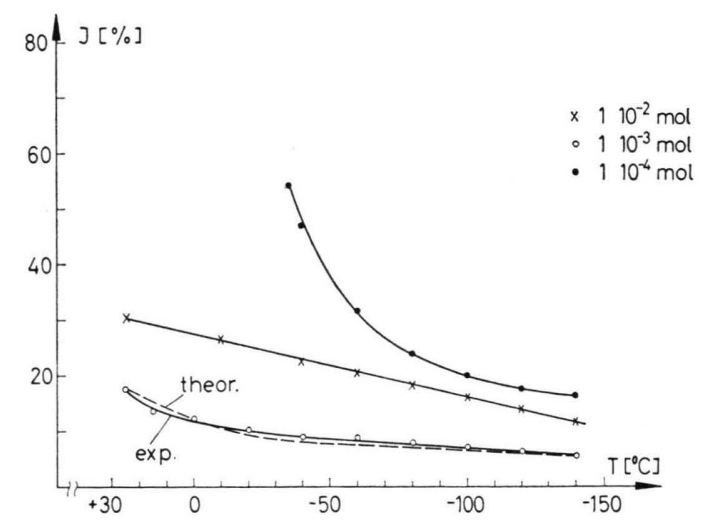

Fig. 6. Threshold intensity $J$ versus temperature $T$ for different concentrations of rhodamin $6 \mathrm{G}$.

\section{Shift of the Emission Wavelength}

The emission of the three investigated dyes showed a shift to shorter wavelengths with decreasing temperature. This shift is produced by reducing the self absorption $\left(\varepsilon_{1}\right)$ near the lasing wavelength and

\begin{tabular}{|c|c|c|c|c|c|c|c|c|c|c|}
\hline & $\begin{array}{l}N \\
{\left[\mathrm{~cm}^{-3}\right]}\end{array}$ & $\begin{array}{l}\varepsilon_{1} \\
{\left[\mathrm{~cm}^{2}\right]}\end{array}$ & $\begin{array}{l}\varepsilon_{3} \\
{\left[\mathrm{~cm}^{2}\right]}\end{array}$ & $\begin{array}{l}\tau \\
\text { [nsec] }\end{array}$ & $R_{1} R_{2}$ & $V$ & $\begin{array}{l}l \\
{[\mathrm{~cm}]}\end{array}$ & $\begin{array}{l}\lambda \\
{[\mathrm{AE}]}\end{array}$ & $\begin{array}{l}E \\
{\left[\mathrm{~cm}^{-1}\right]}\end{array}$ & $\eta$ \\
\hline $\begin{array}{l}T=25^{\circ} \mathrm{C} \\
T=-140^{\circ} \mathrm{C}\end{array}$ & $\begin{array}{l}6 \cdot 10^{17} \\
6 \cdot 10^{17}\end{array}$ & $\begin{array}{l}2 \cdot 10^{-17} \\
2 \cdot 10^{-17}\end{array}$ & $\begin{array}{l}2.2 \cdot 10^{-16} \\
3.4 \cdot 10^{-16}\end{array}$ & $\begin{array}{l}3.5 \\
6.5\end{array}$ & $\begin{array}{l}0.9 \cdot 0.9 \\
0.9 \cdot 0.9\end{array}$ & $\begin{array}{l}0.1 \\
0.1\end{array}$ & $\begin{array}{l}1 \\
1\end{array}$ & $\begin{array}{l}5820 \\
5680\end{array}$ & $\begin{array}{l}0.75 \cdot 10^{5} \\
0.75 \cdot 10^{5}\end{array}$ & $\begin{array}{l}1.5 \\
1.5\end{array}$ \\
\hline
\end{tabular}

Table 1. Used parameters, rhodamin 6G $1 \cdot 10^{-3}$ molar, for two different temperatures $T=+25^{\circ} \mathrm{C}$ and $T=-140{ }^{\circ} \mathrm{C}$. 


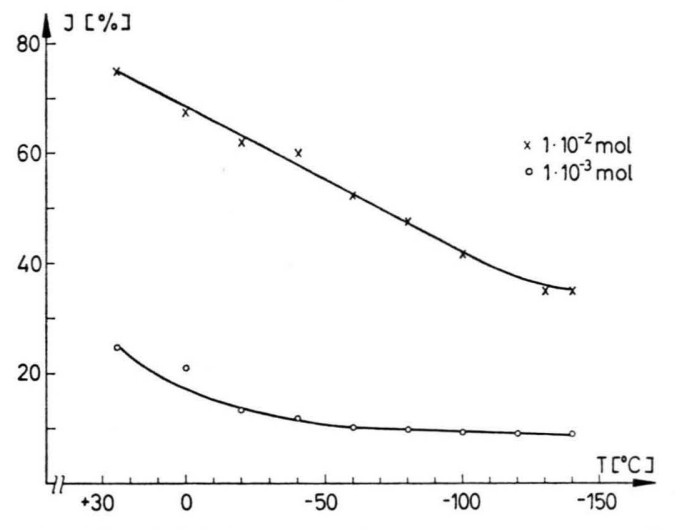

Fig. 7. Threshold intensity $J$ versus temperature $T$ for two different concentratinos of rhodamin $B$.

because of the increase of the fluorescence intensity. The wavelength were measured at threshold.

Rhodamin 6G (Fig. 8): With increasing concentration the temperature shift increases; for $1 \cdot 10^{-2}$ molar the shift is $170 \AA$, for $1 \cdot 10^{-4} \mathrm{~mol}$ only $40 \AA$. The essential shift takes always place between $0{ }^{\circ} \mathrm{C}$ and $-100{ }^{\circ} \mathrm{C}$.

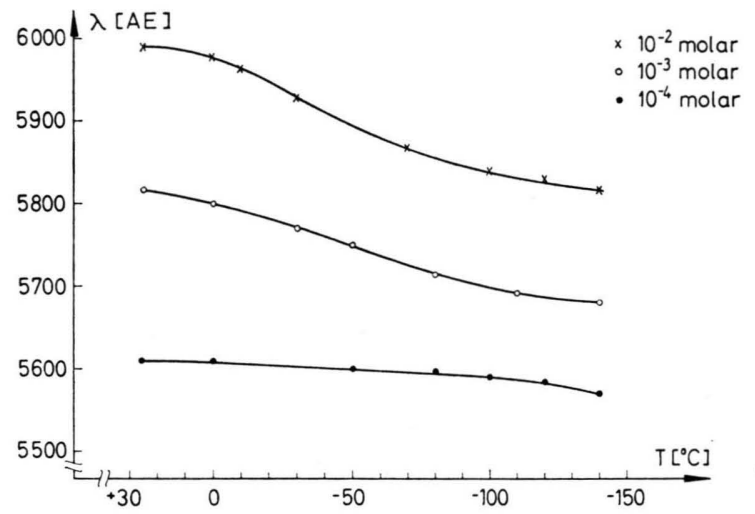

Fig. 8. Wavelength shift versus temperature for different concentrations of rhodamin $6 \mathrm{G}$.

For $1 \cdot 10^{-3}$ molar we have found that the emission always starts at an extinction coefficient $\varepsilon_{1}=$ $0.02 \cdot 10^{-15} \mathrm{~cm}^{2}$; that means that shift is essentially produced by self absorption. The bandwidth of this matrix was $42 \AA$ at threshold and independent of temperature.

Rhodamin $B$ (Fig. 9): Laser action was not possible with concentrations below $1 \cdot 10^{-3}$ molar. The maximum wavelength shift was only $120 \AA$.

Cresylviolet (Fig. 10) : Only with the $1 \cdot 10^{-2}$ molar polyester matrix was it possible to obtain reproducible laser emission. For lower concentrations we used the energy transfer between rhodamin $6 \mathrm{G}$ and cresylviolet ${ }^{12}$.

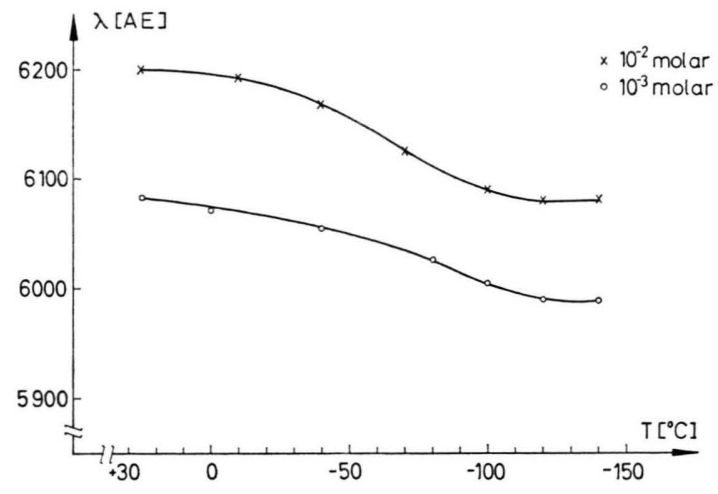

Fig. 9. Wavelength shift versus temperature for two different concentrations of rhodamin $B$.

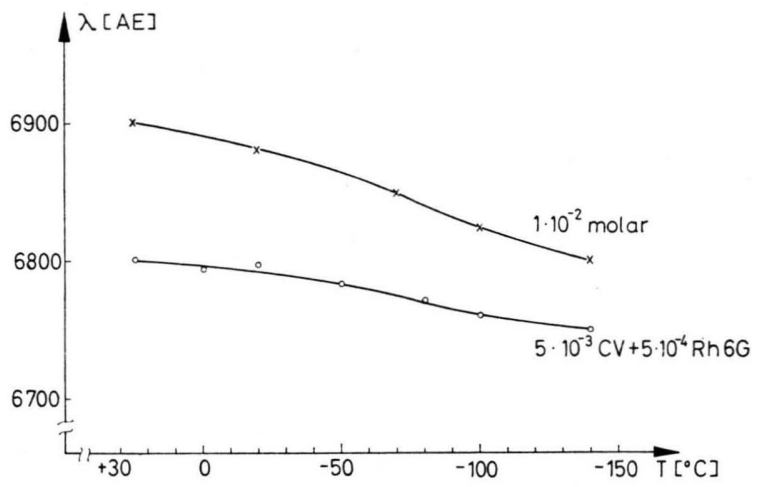

Fig. 10. Wavelength shift versus temperature for cresylviolet $\left(1 \cdot 10^{-2}\right.$ molar $)$ and a mixture of $5 \cdot 10^{-3} \mathrm{~mol}$ cresylviolet and $5 \cdot 10^{-4}$ mol rhodamin $6 \mathrm{G}$.

\section{Output Energy}

The decrease of the threshold implies an increase of the laser output if the exciting intensity is constant. For rhodamin B, rhodamin $6 \mathrm{G}$ and a mixture of cresylviolet and rhodamin $6 \mathrm{G}$ the output energy versus temperature is plotted in Figure 11. The output at $T=+25{ }^{\circ} \mathrm{C}$ is normalized to 1 .

\section{Long Pulse Emission}

Snavely et al. ${ }^{13}$ studied the pulse emission of rhodamin $\mathrm{B}$ and rhodamin 6G in PMMA. They excited the matrix with a flashlamp and got a pulse duration of $t=0.9 \mu \mathrm{sec}$ with rhodamin $\mathrm{B}$ and $t=$ $0.4 \mu \mathrm{sec}$ with rhodamin $6 \mathrm{G}$. Laser emission was terminated by the population of the triplet state of the dye molecule during optical pumping. To minimize this triplet effect in liquid solvents some chemical substances can be added, which increase 


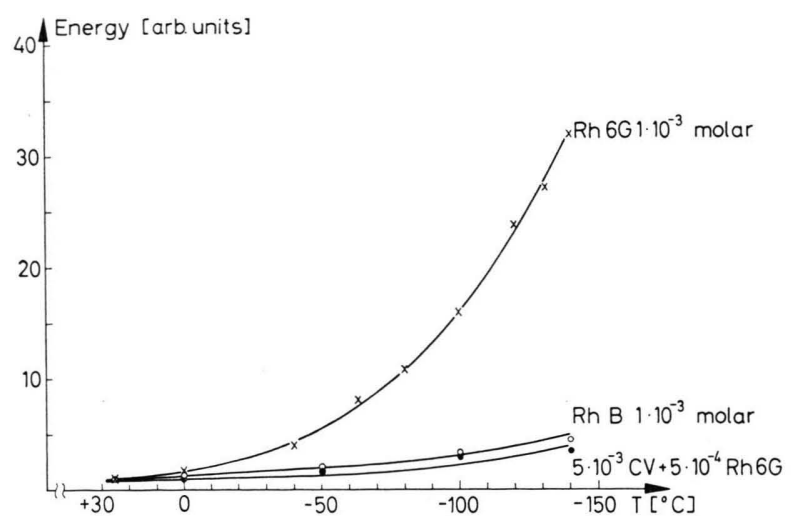

Fig. 11. Output energy versus temperature for rhodamin 6G, rhodamin $\mathrm{B}$ and a mixture of cresylviolet and rhodamin $6 \mathrm{G}$.

depopulation of the triplet. In solid solvents there are two possibilities to reduce this triplet effect. The host material itself can be a triplet quencher; the other way is the reduction of the intersystem crossing rate by cooling. This possibility was proved with a $1 \cdot 10^{-2}$ molar rhodamin $B$ epoxy matrix. The excitation source was a dye laser at $\lambda=5760 \AA$, an output of $6 \mathrm{~m}$ Joule and a pulse duration of $t=$ $2.2 \mu \mathrm{sec}$. The pulse was focused with a cylindrical lens $(f=5 \mathrm{~cm})$. The matrix emission started at $T=-80^{\circ} \mathrm{C}$, and at $T=-140{ }^{\circ} \mathrm{C}$ the pulse duration was $t=1.8 \mu \mathrm{sec}$ at $\lambda=6080 \AA$. The pulse started and ended at the same excitation intensity; so we supposed that there was no strong triplet effect. It was also possible to produce superradiance at $T=-140{ }^{\circ} \mathrm{C}$ with uncoated matrices. The feedback at the matrix surfaces was suppressed by tilting the focus. At small tilt angles superradiance and resonant emission occured simultaneously. The superradiant pulse was shorter $(t=1 \mu \mathrm{sec})$, the wavelength was $\lambda=6060 \AA$.

\section{Photobleaching}

The essential disadvantage of applications of dye matrices as active media is the photobleaching of the organic molecules. The influence of this bleaching on laser output and threshold energy is described in ${ }^{14}$. For several dyes the quantum efficiency of photobleaching is determined by measuring the changing of the absorption spectrum ${ }^{15,16}$. Fork et al. ${ }^{17}$ have indicated that for rhodamin 6G in PMMA the quantum efficiency decreases with decreasing temperature. The quantum efficiency is defined as the ratio of the number of molecules bleached per absorbed photon, but does not respect the interaction between the bleached and unbleached molecules ${ }^{18,19}$. To demonstrate the influence of this interaction on the laser emission we determined the output energy of the matrix as a function of the number of exciting pulses for two different temperatures (Figures 12 and 13). The matrices were excited with the Nd-YAG laser. The excited volume was $V=0.0016 \mathrm{~cm}^{3}$; for $c=1 \cdot 10^{-3}$ molar this corresponds to $N=1.1 \cdot 10^{15}$ molecules. Having emitted $n$ times (see Table 2) the output decreased from $100 \%$ to $90 \%$.

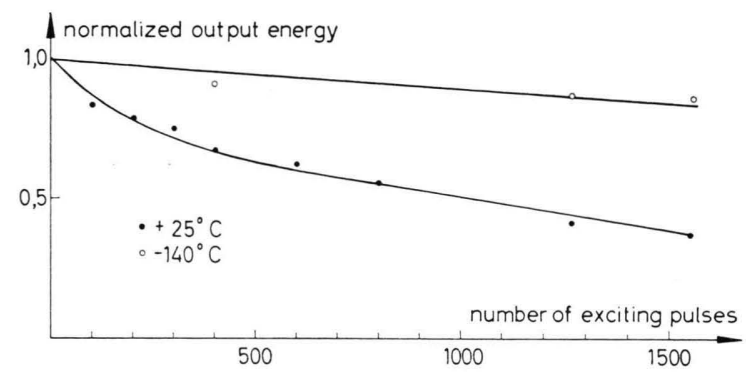

Fig. 12. Normalized output energy versus the number of exciting pulses; rhodamin $6 \mathrm{G} 1 \cdot 10^{-3}$ molar in epoxy for $T=+25^{\circ} \mathrm{C}$ and $T=-140{ }^{\circ} \mathrm{C}$.

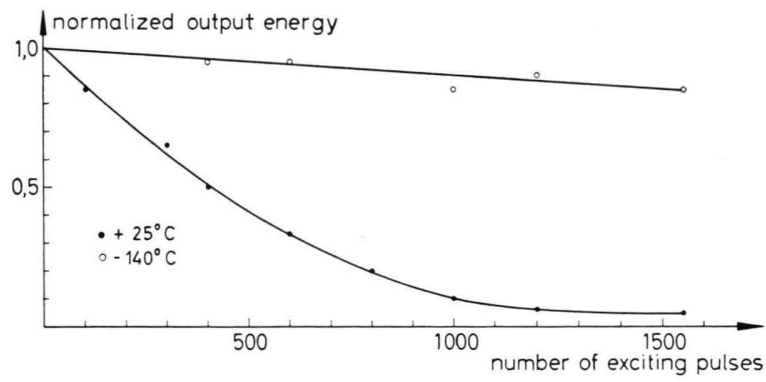

Fig. 13. Normalized output energy versus the number of exciting pulses; rhodamin B $1 \cdot 10^{-3}$ molar in epoxy for $T=+25{ }^{\circ} \mathrm{C}$ and $T=-140{ }^{\circ} \mathrm{C}$.

Table 2. Number $n$ of pulses after which the output is decreased to $90 \%$, for two different temperatures.

\begin{tabular}{lll}
\hline & $T=+25^{\circ} \mathrm{C}$ & $T=-140{ }^{\circ} \mathrm{C}$ \\
\hline Rhodamin 6G & $n=\sim 70$ & $n=\sim 1000$ \\
Rhodamin B & $n=\sim 70$ & $n=\sim 1000$ \\
\hline
\end{tabular}

If we assume the quantum efficiency of photobleaching in PMMA to be the basis of the calculation, $N^{\prime}$ molecules are bleached after 70 pulses $\left(N^{\prime}=\right.$ $6 \cdot 10^{11}$ for $\mathrm{Rh} 6 \mathrm{G}, N^{\prime}=19 \cdot 10^{11}$ for Rh B). This leads to the conclusion that for rhodamin $6 \mathrm{G} 0.06 \%$ 
and for rhodamin B $0.2 \%$ bleached molecules are enough to reduce the output to $90 \%{ }^{14}$. When we cooled the matrice the output decreased to $90 \%$ after 1000 pulses. The bleaching rate at $T=$ $-140{ }^{\circ} \mathrm{C}$ was $0.4 \cdot 10^{7}$ and the number of bleached molecules is again $N^{\prime}=6 \cdot 10^{11}$ for rhodamin $6 \mathrm{G}$ (for rhodamin $\mathrm{B}$ the bleaching rate at $T=-140{ }^{\circ} \mathrm{C}$ is unknown).

1 Dye Laser, F. P. Schäfer, Springer-Verlag, Berlin 1973.

2 G. T. Schappert, K. W. Billmann, and D. C. Burnham, Appl. Phys. 13, Nr. 4 [1968].

3 A. V. Aristov and Y. S. Mashjukov, Opt. Spectrosc. 24, 450 [1968].

4 B. G. Huth, G. J. Farmer, and M. R. Kagan, J. Appl. Phys. 40, Nr. 13 [1969].

5 J. Ferguson and A. W. H. Mau, Chem. Phys. Letters 14, 245 [1972].

6 W. L. Lewschin, Z. Physik 72, 382 [1931].

7 W. E. Speas, Phys. Rev. 31, 569 [1928].

8 J. Muto, Keio Engineering Reports 25, 6 [1972].

9 F. J. Theiß and J. Weber, Opt. Communications 12, 368 [1974].
This small amount indicates that the decrease of the concentration is not responsible for the output change but the interaction, probably by fluorescence quenching.

The authors wish to thank Mrs. Ostwaldt for fabrication assistance.

10 J. Weber, Z. Phys. 258, 277 [1973].

11 B. B. Snavely, Proceedings IEEE 57, Nr. 8 [1969].

12 W. Schmidt, W. Appt, and N. Wittekindt, Z. Naturforsch. 27 a, 37 [1972].

13 O. G. Peterson and B. B. Snavely, Appl. Phys. Letters 12, Nr. 7 [1968].

14 J. Weber, Z. angew. Physik 31, 7 [1971].

15 E. P. Ippen and C. V. Shank, JEEEQE 7, 178 [1971].

16 J. Weber, Phys. Letters 45 A, 35 [1973].

17 R. L. Fork and Z. Kaplan, Appl. Phys. Letters 20, 472 [1972].

18 J. Weber, Physics Letters 37 A, 179 [1971].

19 D. Kato and A. Sugimura, Optics Communications 10, 327 [1974]. 